\title{
Gluteal-fold flap repair of rectovaginal fistula caused by aluminum potassium sulfate hydrate-tannic acid injection for internal hemorrhoids: a case report
}

\author{
Masanori Yoshimitsu ${ }^{1 *}$ (D), Hiroyuki Egi ${ }^{2}$, Shogo Nagamatsu ${ }^{3}$, Manabu Shimomura $^{4}$, Keishi Hakoda ${ }^{2}$, \\ Masashi Miguchi ${ }^{5}$, Toshihiko Kohashi ${ }^{4}$, Masazumi Okajima ${ }^{1}$ and Hideki Ohdan ${ }^{2}$
}

\begin{abstract}
Background: Rectovaginal fistula (RVF) following aluminum potassium sulfate hydrate-tannic acid (ALTA) injection therapy for hemorrhoids is a rare complication. We report the first case of RVF after ALTA injection therapy successfully treated by gluteal-fold flap.

Case presentation: A 49-year-old female suffered from a fever and rectal ulcer after undergoing internal hemorrhoid treatment with a submucosal ALTA injection at a previous clinic. One week after ALTA therapy, she noted obvious passage of flatus and stool through the vagina, and was diagnosed with RVF by anoscope at another clinic. She was referred to our hospital 3 weeks after ALTA therapy. Sigmoid colostomy was performed for fecal diversion as a preliminary step for fistula repair. However, the fistula was scarred and the defect between the rectum and vagina did not improve at all. Ten months after ALTA therapy, we performed fistula repair by glutealfold flap. Seven months later, sigmoid-colostomy reversal was performed. The patient has experienced no RVF in the 3 years since sigmoid-colostomy reversal.
\end{abstract}

Conclusions: The gluteal-fold flap strategy is a useful option for severe RVF management.

Keywords: ALTA, Internal hemorrhoids, RVF, Gluteal-fold flap

\section{Background}

Rectovaginal fistulas (RVF) are abnormal communications between the rectum and vagina. RVF may be caused by obstetric trauma, inflammatory bowel disease, radiation proctitis, and rectal operations such as stapled anterior resections. In this case, RVF occurred following aluminum potassium sulfate hydrate and tannic acid (ALTA) therapy for internal hemorrhoids. ALTA (Zion, Mitsubishi Pharma Corp., Osaka, Japan) is a new sclerosant developed in Japan [1, 2]. ALTA therapy is effective for shrinking and hardening the hemorrhoids in order to

\footnotetext{
* Correspondence: myoshimitsu1970@gmail.com

'Department of Surgery, Hiroshima City Hiroshima Citizens Hospital, 7-33

Motomachi Naka-Ku, Hiroshima 730-8518, Japan

Full list of author information is available at the end of the article
}

eliminate prolapse and bleeding. Reported post-operative complications have included a slight fever, ischuria, anal pain, and rectal ulcer, most of which improved through conservative treatment [3-5]. However, in rare cases, RVF has been reported following ALTA therapy. Various surgical methods to repair RVF have been reported, but there are no clear guidelines regarding the management of these fistulas [6,7]. This is the first reported case of successful use of a gluteal-fold flap to repair a severe RVF after ALTA therapy for hemorrhoids.

\section{Case presentation}

A 49-year-old female suffered from a fever and rectal ulcer after undergoing internal hemorrhoid treatment with a submucosal injection of ALTA at a previous 

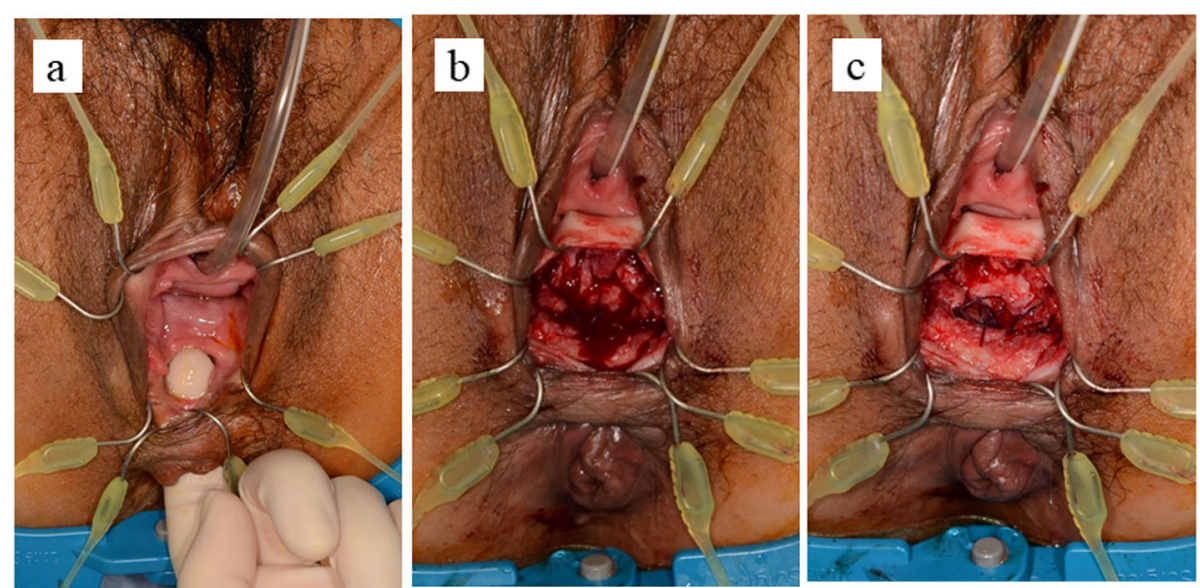

Fig. 1 Intraoperative views of the rectovaginal fistula. (a) Rectovaginal fistula before repair; (b) after fistulectomy; (c) the rectal wall defect is closed and the vaginal defect is opened

clinic. Detailed information concerning the ALTA therapy was not available. One week after ALTA therapy, she noted the obvious passage of flatus and stool through the vagina. She was diagnosed with RVF by anoscope in another clinic and referred to our hospital 3 weeks after ALTA therapy. A sigmoid colostomy was performed for fecal diversion as a preliminary step for fistula repair. The fistula did not improve at all (Fig. 1a). She had no symptoms such as pain and fever caused by severe damage of the surrounding tissue. However, she had been suffering from poor QOL as an ostomate. Ten months after ALTA therapy, we performed RVF repair by gluteal-fold flap. Under general anesthesia, the patient was placed in the lithotomy position. The $2 \mathrm{~cm}$ fistula at the vaginal entrance was easy to manipulate under direct vision. A fistulectomy was performed to dissect the fistula tract and the circumferential scar tissue (Fig. 1b). The rectal defect was closed primarily with interrupted absorbable sutures through the vaginal side. The vaginal wall was not sutured, and the space above the sutured rectal wall was opened (Fig. 1c).

A Doppler probe was used to identify and mark the points of the perforator vessels of the internal pudendal artery on the medial point of the right ischial tubercle. A gluteal-fold flap was designed around the right gluteal fold including these marked points (Fig. 2a), the entire
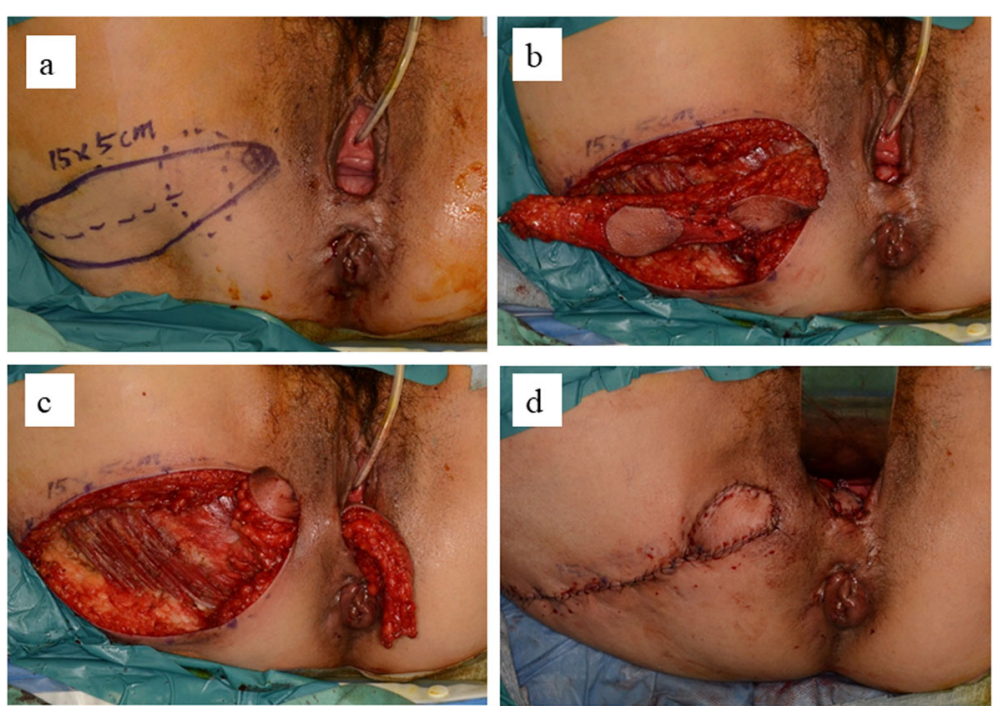

Fig. 2 Intraoperative views of the gluteal fold flap. a Perforator vessels of the internal pudendal artery are identified with a Doppler probe and marked on the medial point of the right ischial tubercle. A $5 \times 15 \mathrm{~cm}$ diamond-shaped flap of skin, subcutaneous fat, and superficial fascia is designed. $\mathbf{b}$ Perforators of the internal pudendal artery in the fatty tissue act as a pedicle and provide skin flap circulation. c The gluteal-fold flap is rotated counter-clockwise through a subcutaneous tunnel and placed in the space above the rectal wall. $\mathbf{d}$ The donor site is closed and the skin flap is sutured to the vaginal wall defect. The skin flap is observed in the vaginal vestibule 
circumference of the skin was incised, and the distal side of the flap was elevated from the subcutaneous muscular layer. The proximal subcutaneous flap fat under the Doppler marking was left attached to the muscle to avoid injury to the pedicle vessel (Fig. 2b). After confirming the pedicle vessel of the flap, the flap was carefully elevated with blunt dissection. A subcutaneous tunnel to the vaginal introitus was prepared to minimize tension on the gluteal flap, and the flap was rotated 180 degrees and transferred through the tunnel to cover the posterior vaginal mucosal defect. The proximal skin portion of the flap was denuded and conformed to the shape of the posterior vaginal mucosal defect, and the subcutaneous fat tissue on the distal area of the flap was removed to thin the flap, while confirming bleeding from the flap margin (Fig. 2c). The flap was sutured to the surrounding vaginal wall with absorbable interrupted horizontal mattress sutures (Fig. 2d). Before donor site skin closure, a small suction drain was placed in the gracilis muscle harvested space. We show the illustrations of the operative procedure in Fig. 3. The patient had open drainage for subcutaneous abscess and was discharged on the 21st postoperative day. Seven

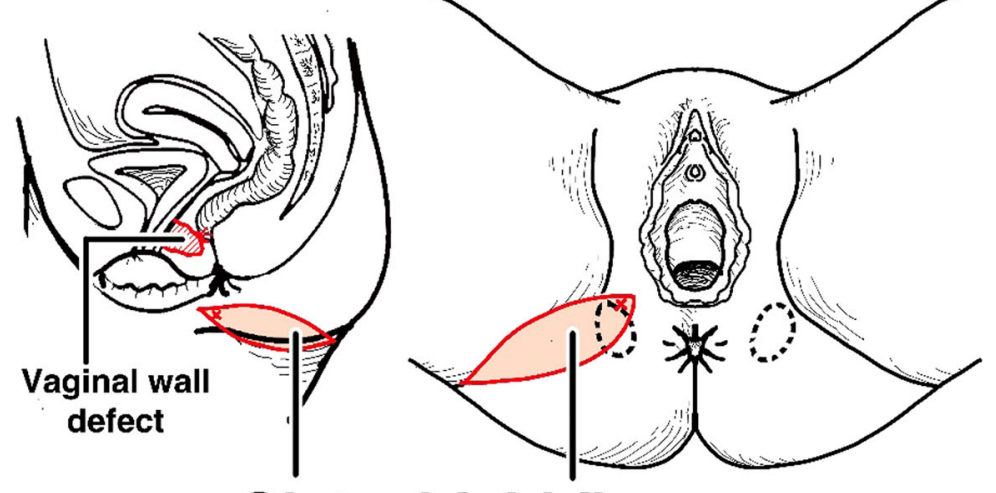

Gluteal fold flap

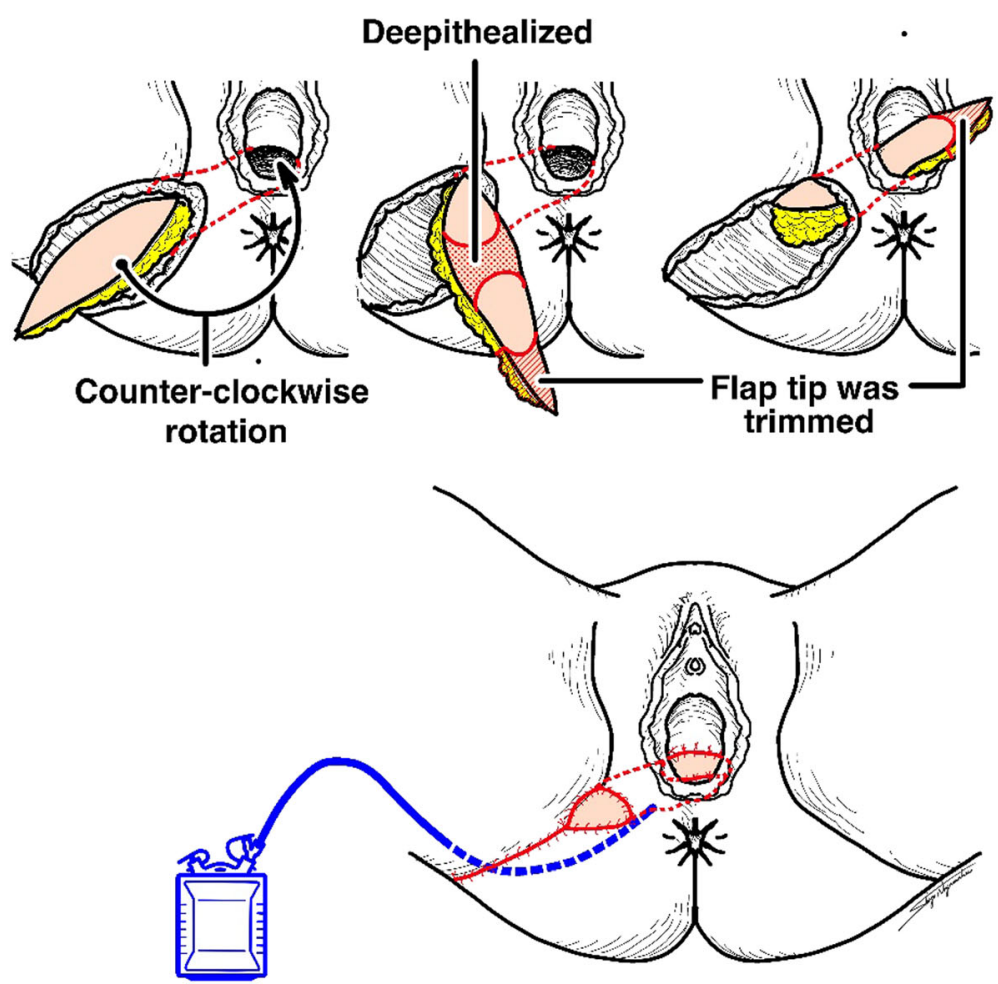

Fig. 3 The illustrations of the operative procedure 
months after the radical operation, we confirmed the fistula repair by pelvic examination of the vaginal wall and colonoscopic exam of the anorectal wall (Fig. 4). Sigmoidcolostomy reversal was performed. The patient has experienced no RVF and complete anal function without soiling and has not been trying to do sexual intercourse in the three years since the sigmoid-colostomy reversal.

\section{Discussion}

This is the first reported case of successful glutealfold flap repair of severe RVF caused by ALTA therapy for the treatment of internal hemorrhoids. While iatrogenic RVF is known to be a rare, debilitating complication following the treatment of rectal cancer, there are no reports of refractory RVF following ALTA therapy in medical databases such as PubMed. These fistulas do not have the propensity to heal spontaneously and are challenging to repair. The fistula in this case was further complicated as it was fixed with scar tissue. Various surgical methods to repair these fistulas have been reported. However, RVF repairs sometimes break down when patients undergo multiple repairs $[7,8]$. The gluteal-fold flap is one of the various muscle and skin flap repairs for the treatment of fistulas. A gluteal-fold flap is sufficiently wide and long to ensure adequate vascular supply and good mobility, providing a reliable surgical treatment for patients with severe and iatrogenic RVF [8-10].

ALTA, a new and effective sclerosant, was developed in Japan and is effective for shrinking and hardening hemorrhoids in order to eliminate prolapse and bleeding [1, 2]. ALTA therapy combines aluminum potassium sulfate and tannic acid; the former induces an inflammatory reaction, resulting in strong, local fibrosis, while the latter has a strong astringent effect on tissue, promoting protein coagulation and the contraction of blood vessels while reducing exudation into the tissue from the inflammatory reaction $[1,2]$. ALTA sclerotherapy is popular as a comparatively simple, minimally invasive treatment for symptomatic internal hemorrhoids in outpatient clinics in Japan [3-5]. The symptoms of concern vanish practically on the first post-operative day. Patients usually experience little postoperative pain and no serious complications, and they report high satisfaction. ALTA therapy can be performed for patients suffering from Goligher's grade II and III hemorrhoids in an outpatient setting [3].

While several reports have described post-operative complications including a slight fever, ischuria, anal pain, and rectal ulcer, most cases improved through conservative treatment, and no serious or lifethreatening complications occurred [3-5]. However, ALTA damages tissue, and complications such as rectal ulcer and rectal stenosis have been reported due to the misplacement of injections [5]. In this case, detailed information from the previous clinic about the ALTA injection procedure could not be obtained. However, we guessed the RVF was caused by ALTA injection in vaginal side. The ALTA injection in front side requires close attention. Of note, this is the only local Japanese clinic to report a case of RVF associated with ALTA therapy for internal hemorrhoids. Conservative treatment, such as diverting ileostomy, has proven effective in treating RVF. However, in this case, the severe, scarred fistula could not heal spontaneously. Consequently, a challenging surgical repair was required.

\section{Conclusions}

This is the first reported case of severe RVF caused by ALTA therapy for the treatment of internal hemorrhoids and successfully managed by gluteal-fold flap. RVF is a very rare and refractory complication of ALTA therapy that may be associated with misplaced injections. The gluteal-fold flap method used in the present case is a useful option for severe RVF management.

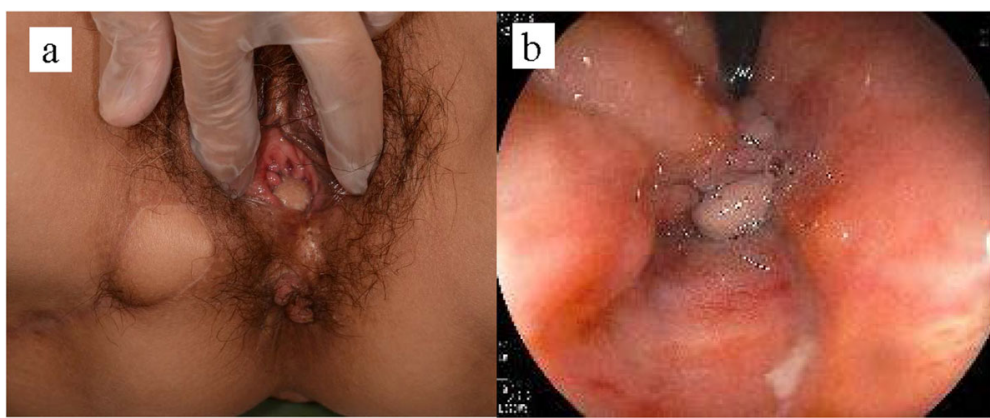

Fig. 4 The healed site 6 months after the operation. a The gluteal-fold flap is seen in the vaginal vestibule with no fistula recurrence. b Colonoscopy shows no recurrence on the anorectal wall side 


\section{Abbreviations}

ALTA: Aluminum potassium sulfate hydrate-tannic acid; RVF: Rectovaginal fistula

\section{Acknowledgements}

We would like to thank Editage (www.editage.com) for English language editing.

\section{Authors' contributions}

M. Yoshimitsu drafted the manuscript. H. Egi supervised the preparation of the manuscript. S. Nagamatsu contributed to the reconstructive surgery using flap and the illustrations of the surgical procedures. K Hakoda and M Miguchi contributed to the anorectal operation. MS, TK, MO, and HO reviewed and modified the manuscript. The authors read and approved the final manuscript.

\section{Authors' information}

None declared.

\section{Funding}

None declared.

\section{Availability of data and materials}

The data presented in this article is not publicly available due to patient privacy concerns.

\section{Ethics approval and consent to participate}

Not applicable.

\section{Consent for publication}

The patient has provided written informed consent for the publication of data and images.

\section{Competing interests}

The authors declare that they have no competing interests.

\section{Author details}

'Department of Surgery, Hiroshima City Hiroshima Citizens Hospital, 7-33 Motomachi Naka-Ku, Hiroshima 730-8518, Japan. ${ }^{2}$ Department of Gastroenterological and Transplant Surgery, Applied Life Sciences, Institute of Biomedical \& Health Sciences, Hiroshima University, Hiroshima, Japan. ${ }^{3}$ Department of Plastic Surgery, Hiroshima University, Hiroshima, Japan. ${ }^{4}$ Department of Surgery, Hiroshima City Asa Citizens Hospital, Hiroshima, Japan. ${ }^{5}$ Department of Surgery, Hiroshima Prefectural Hospital, Hiroshima, Japan.

Received: 9 May 2020 Accepted: 25 June 2020

Published online: 08 July 2020

\section{References}

1. Ono T, Goto K, Takagi S, Iwasaki S, Komatsu H. Sclerosing effect of OC-108, a novel agent for hemorrhoids, is associated with granulomatous inflammation induced by aluminum. Journal of pharmacological sciences. 2005:99(4):353-63.

2. Ono T, Nakagawa H, Fukunari A, Hashimoto T, Komatsu H. Hemostatic action of OC-108, a novel agent for hemorrhoids, is associated with regional blood flow arrest induced by acute inflammation. Journal of pharmacological sciences. 2006:102(3):314-20.

3. Miyamoto $H$, Hada $T$, Ishiyama $G$, Ono $Y$, Watanabe $H$. Aluminum potassium sulfate and tannic acid sclerotherapy for Goligher grades II and III hemorrhoids: results from a multicenter study. World journal of hepatology. 2016;8(20):844-9.

4. Tomiki Y, Aoki J, Motegi S, Takahashi R, Hagiwara T, Okazawa Y, et al. Effectiveness of endoscopic sclerotherapy with aluminum potassium sulfate and tannic acid as a non-surgical treatment for internal hemorrhoids. Clinical endoscopy. 2019;52(6):581-7.

5. Tomiki Y, Ono S, Aoki J, Takahashi R, Ishiyama S. Sugimoto K, et al. Treatment of internal hemorrhoids by endoscopic sclerotherapy with aluminum potassium sulfate and tannic acid. diagnostic and therapeutic endoscopy. 2015;2015:517690.
6. Samalavicius NE, Gupta RK. Graciloplasty for the rectovaginal fistula after chemoradiation followed by total mesorectal excision for rectal cancer. Archives of Iranian medicine. 2013;16(1):54-5.

7. Koganei K, Kimura H, Sugita A, Arai K, Fukushima T, Shimada H. [Clinical experiences of five cases with ulcerative colitis and recto- or anovaginal fistula]. Nihon Shokakibyo Gakkai zasshi = The Japanese journal of gastroenterology. 2006;103(12):1355-60.

8. Kosugi C, Saito N, Kimata Y, Ono M, Sugito M, Ito M, et al. Rectovaginal fistulas after rectal cancer surgery: incidence and operative repair by glutealfold flap repair. Surgery. 2005;137(3):329-36.

9. Onishi K, Ogino A, Saida Y, Maruyama Y. Repair of a recurrent rectovaginal fistula using gluteal-fold flap: report of a case. Surgery today. 2009;39(7): 615-8.

10. Shahzad F, Wong KY, Di Candia M, Menon M, Malata CM. Gluteal fold flap in perineal reconstruction for Crohn's disease-associated fistulae. Journal of plastic, reconstructive \& aesthetic surgery: JPRAS. 2014;67(11):1587-1590.

\section{Publisher's Note}

Springer Nature remains neutral with regard to jurisdictional claims in published maps and institutional affiliations.

\section{Submit your manuscript to a SpringerOpen ${ }^{\circ}$ journal and benefit from:}

- Convenient online submission

- Rigorous peer review

- Open access: articles freely available online

High visibility within the field

- Retaining the copyright to your article

Submit your next manuscript at $\boldsymbol{\nabla}$ springeropen.com 